\title{
Peritoneal Ventilation: An Animal Model of Extrapulmonary Ventilation in Experimental Adult Respiratory Distress Syndrome
}

\author{
J. BARR, A. LIVNE, G. LUSHKOV, I. VINOGRAD, Y. EFRATI, A. BALLIN, E. LAHAT, AND G. ESHEL
}

Pediatric Intensive Care Unit [J.B., A.L., E.L., G.E.], The Laboratory for Surgical Research [G.L., A.B.], and The Department of Pediatric Surgery [I.V., Y.E.], Assaf Harofeh Medical Center, Sackler Faculty of Medicine. Tel Aviv University, Zerifin, Israel

\begin{abstract}
Adult respiratory distress syndrome (ARDS) is a critical medical problem in which severe arterial hypoxemia is often poorly responsive to conventional modes of mechanical ventilation. We studied the efficiency of mechanical ventilation of the peritoneal cavity in rabbits with experimental ARDS caused by lung lavage. The study shows that peritoneal ventilation is significantly effective in oxygenation of hypoxemic animals with ARDS and is also effective for carbon dioxide elimination. Peritoneal ventilation may be considered as an investigational method for extrapulmonary oxygenation in severe intractable hypoxemia caused by ARDS. (Pediatr Res 35: 682-684, 1994)
\end{abstract}

\section{Abbreviations}

ARDS, adult respiratory distress syndrome

PEEP, positive end expiratory pressure

$\mathrm{FIO}_{2}$, fraction of inspired oxygen

ABG, arterial blood gases

$\mathrm{PaO}_{2}$, arterial $\mathrm{PO}_{2}$

$\mathrm{PaCO}_{2}$, arterial $\mathrm{PCO}_{2}$

Persistent hypoxemia caused by severe ARDS is a common medical condition that frequently responds poorly to conventional methods of artificial lung ventilation. The novel technique of extracorporeal membrane oxygenation is not always available or possible. The peritoneum, especially the omentum, is a large (1), absorptive, highly permeable surface with a rich vascular bed and therefore is a potential organ for extrapulmonary gas exchange. Looking for methods to improve arterial oxygenation in patients with severe pulmonary dysfunction, investigators have tried various extrapulmonary ways to supply oxygen, such as i.v. infusion of gaseous oxygen to experimental animals $(2,3)$ and to sick humans (4). Other studies in the past evaluated peritoneal oxygenation by direct insufflation of gaseous oxygen into the peritoneal cavity $(2,5)$ or peritoneal dialysis with oxygenated solutions $(6-10)$.

We have tested the method of extrapulmonary oxygenation by mechanically ventilating the peritoneal cavity of rabbits that served as an experimental model of ARDS. A control group of rabbits with ARDS was treated with conventional lung ventilation. Our study clearly demonstrates that acceptable arterial oxygenation and carbon dioxide elimination can be achieved by

Received July 23, 1993; accepted January 26, 1994.

Correspondence: Dr. J. Barr. Pediatric Intensive Care Unit, Assaf Harofeh Medical Center, Zerifin 70300, Israel. mechanical ventilation of the peritoneal cavity in rabbits with severe ARDS. Peritoneal ventilation may be considered as an investigational method for extrapulmonary oxygenation in severe intractable hypoxemia caused by ARDS.

\section{MATERIALS AND METHODS}

Eleven healthy white rabbits, weighing $2.5-3.5 \mathrm{~kg}$, were managed according to NIH regulations and the Guiding Principles in the Care and Use of Animals of the American Physiological Society. The study was performed with the approval of the local animal care committee. The rabbits were anesthetized with a ketamine-xylazine combination $(11,12)$.

Intubation was done with endotracheal tube no. 3.5 (Portex Ltd., England). Mechanical ventilation was started with a Bennet ventilator (Puritan-Bennett Corp.). Initial settings were: mode $=$ intermittent mandatory ventilation (time cycled, pressure preset), respiratory rate $=18 / \mathrm{min}, \mathrm{PEEP}=2 \mathrm{~cm} \mathrm{H}_{2} \mathrm{O}$, maximum pressure $=24 \mathrm{~cm} \mathrm{H}_{2} \mathrm{O}$, and $\mathrm{FIO}_{2}=1.00$.

An i.v. infusion $(12 \mathrm{~mL} / \mathrm{h})$ of saline $0.45 \%$-glucose $5 \%$ was given via an ear vein. An arterial line was inserted in an ear artery, intermittently flushed with heparinized saline, and used for blood sampling for ABG and for intermittent systolic blood pressure measurements (recorded in $\mathrm{cm} \mathrm{H}_{2} \mathrm{O}$ ) using a saline column during the study.

After 15 min of stabilization, baseline ABG were checked. The rabbits were then randomized into two groups. Group $A$, the trial group, had five rabbits. The rabbits in this group were treated with peritoneal ventilation in parallel with conventional ventilation of the lungs. Group B, the control group, had six rabbits. The rabbits in this group were treated only with mechanical ventilation of the lungs.

After conventional mechanical ventilation was started, a catheter (argyle Trocar catheter, size $24 \mathrm{Ch}$; ARGYLE Division of Sherwood Medical, Ireland) was inserted into the peritoneal cavity of the rabbits in both groups using a procedure similar to that for insertion of a catheter for acute peritoneal dialysis. At this stage, the pulmonary lavage was started, causing ARDS in both groups. Previous studies have described various comparable methods of pulmonary lavage (13-15). We used a similar lavage technique: $20 \mathrm{~mL}$ of normal saline per $\mathrm{kg}$ per cycle $\left(\right.$ at $37^{\circ} \mathrm{C}$ ) were injected in aliquots of $20 \mathrm{~mL}$ five times into the endotracheal tube, and the fluid was allowed to exit freely via the tube after each of the five cycles. The tube was intermittently disconnected from the ventilator tubing for periods of less than $8 \mathrm{~s}$ while the saline was injected into the tube and while the saline was allowed to exit the lungs. The mechanical respiratory rate of the lungs was increased to $44 / \mathrm{min}$ after completion of the lavage in both groups to prevent carbon dioxide accumulation and respiratory acidosis, but no other ventilatory changes were made. 
After the lavage was finished, the peritoneal cavity of each rabbit in group A was mechanically ventilated with a Bennet ventilator, with the settings as follows: mode $=$ intermittent mandatory ventilation (time cycled, pressure preset), $\mathrm{FIO}_{2}=$ 1.00 , respiratory rate $=30 / \mathrm{min}$, maximum pressure $=8 \mathrm{~cm}$ $\mathrm{H}_{2} \mathrm{O}$, and PEEP $=2 \mathrm{~cm} \mathrm{H}_{2} \mathrm{O}$. The peritoneal catheter in group $B$ was closed and not used. ABG were checked at 15, 30, 60, 90, and $120 \mathrm{~min}$. The study was completed in $2 \mathrm{~h}$.

Data were collected in dBASE IV, a database program. Statistical analysis ( $\chi^{2}$ test and two-sample $t$ test) was done with Statistix version 3.1 analytical software. Alveolar-arterial $\mathrm{PO}_{2}$ differences $\left(\mathrm{A}-\mathrm{aDO}_{2}\right)$ were calculated as follows (16):

$$
\mathrm{A}-\mathrm{aDO}_{2}=\mathrm{PAO}_{2}-\mathrm{PaO}_{2}
$$

where $\mathrm{PAO}_{2}=$ alveolar $\mathrm{PO}_{2} . \mathrm{PAO}_{2}$ can be calculated as follows: $\mathrm{PAO}_{2}=\left(\mathrm{PB}-\mathrm{PH}_{2} \mathrm{O}\right) \cdot \mathrm{FIO}_{2}-\mathrm{PaCO}_{2} / \mathrm{R}+\mathrm{PaCO}_{2} \cdot \mathrm{FIO}_{2} \cdot(1-\mathrm{R}) /$ $\mathrm{R}$, where $\mathrm{PB}=$ barometric pressure $=101.33 \mathrm{kPa}, \mathrm{PH}_{2} \mathrm{O}=$ partial pressure of lung water vapor at $37^{\circ} \mathrm{C}=6.27 \mathrm{kPa}$, and $\mathrm{R}$ $=$ respiratory quotient $=0.8$.

\section{RESULTS}

Table 1 shows the mean values of $\mathrm{PaCO}_{2}, \mathrm{PaO}_{2}, \mathrm{~A}-\mathrm{aDO}$, and systolic blood pressures recorded from the two groups. Baseline $\mathrm{PaO}_{2}$ and $\mathrm{PaCO}_{2}$ values in both groups were similar. Soon after the lavage, the rabbits in group B developed severe hypoxemia and mild hypercapnia; both parameters were significantly worse than those of the rabbits in group A $(p<0.05)$.

Group A initially included five rabbits. One rabbit in this group died unexpectedly at $50 \mathrm{~min}$ after the lavage. Group B initially included six rabbits. The animals in this group became extremely hypoxemic soon after the lavage. One rabbit died 12 min after the lavage, three rabbits died in 20-25 min, the fifth rabbit died in $50 \mathrm{~min}$, and the last one in $75 \mathrm{~min}$. The mortality rate difference between the two groups is statistically significant $(p=0.006)$.

Table 1 clearly illustrates the beneficial effect of peritoneal ventilation on severely hypoxemic animals with experimental ARDS: a significant increase in $\mathrm{PaO}_{2}$ and a significant decrease in $\mathrm{PaCO}_{2}$. Figure 1 shows the chest $\mathrm{x}$-ray of a rabbit with severe ARDS $1 \mathrm{~h}$ after the lavage.

\section{DISCUSSION}

Persistent hypoxemia due to severe lung disease is not rare. ARDS is a common and important medical problem in which arterial hypoxemia is sometimes poorly responsive to supplemental oxygen or positive pressure ventilation. Patients with severe ARDS usually demonstrate extreme hypoxemia and marked hypocapnia. Various methods of mechanical ventilation, including use of a high PEEP level, $\mathrm{FIO}_{2}=1.00$, inverse $\mathrm{I}: \mathrm{E}$ ratio, pressure control inverse ratio ventilation, and other methods are unsatisfactory in some instances and fail to adequately oxygenate patients with severe ARDS. Extracorporeal membrane oxygenation done by pulmonary bypass is used in few specialized centers, inasmuch as it has its own contraindications (e.g. intracranial hemorrhage), complications (e.g. thrombocytopenia), and special requirements (e.g. anticoagulation, cannulation of central vessels, a trained team, and high costs).

The peritoneum, especially the omentum, is a large, absorptive, highly permeable surface with a rich vascular bed and is a potential organ for extrapulmonary gas exchange. The total peritoneal surface area in the adult is nearly $2 \mathrm{~m}^{2}(1)-$ much smaller than the alveolar surface area, which is $50-100 \mathrm{~m}^{2}$ in the adult (16).

Looking for methods to improve arterial oxygenation in patients with severe pulmonary dysfunction, investigators have tried various extrapulmonary ways to supply oxygen, such as i.v. infusion of gaseous oxygen to experimental animals $(2,3)$ and sick humans (4).

The peritoneal cavity was studied only a few times in the past as an organ for extrapulmonary oxygenation $(2,5-10)$. Several studies have checked the ability to oxygenate hypoxic animals by continuously infusing gaseous oxygen into the peritoneal cavity of hypoxemic animals $(2,5)$. Others have studied the effect of oxygenated fluid infusion in the peritoneal cavity $(6-10)$. The lungs of the animals in a study (5) were not damaged before the peritoneal oxygenation was started, and hypoxemia was achieved by ventilation with subnormally low $\mathrm{FIO}_{2}$. This fact was later considered to be the cause of nonsignificant improvement in arterial oxygenation, because the venous $\mathrm{PO}_{2}$ was higher than the alveolar $\mathrm{PO}_{2}$ and the oxygen that entered the body via the peritoneum was then lost from the vascular bed to the normal pulmonary alveoli (5). We performed extrapulmonary oxygenation by using conventional mechanical ventilation of the peritoneal cavity with gaseous warmed and humidified oxygen, as in lung ventilation.

The results of our short-term study clearly demonstrate the significant improvement $(p<0.05)$ in arterial oxygenation and carbon dioxide elimination in the rabbits with ARDS treated with the combination of lung and peritoneal ventilation. The rabbits in the control group, treated solely with lung ventilation, died after $34 \pm 24$ min (mean \pm SD). The rabbits (except for one) on combined lung and peritoneal ventilation (group A) survived the entire duration of the experiment and maintained acceptable hemodynamic and respiratory parameters.

Peritoneal ventilation can serve as an auxiliary extrapulmonary method for improving oxygenation of patients with acute intractable hypoxemia with or without carbon dioxide retention. The method is simple, available, and easy to perform. The

Table 1. $\mathrm{ABG}(\mathrm{kPa})$ and $\mathrm{SBP}\left(\mathrm{cm} \mathrm{H}_{2} \mathrm{O}\right)$ of ventilated rabbits with and without peritoneal ventilation*

\begin{tabular}{|c|c|c|c|c|c|c|c|}
\hline Group & $\mathrm{B} / \mathrm{L}$ & $15 \min A / L$ & $30 \min A / L$ & $60 \mathrm{~min} A / L$ & $90 \min \mathrm{A} / \mathrm{L}$ & $120 \min \mathrm{A} / \mathrm{L}$ & $\begin{array}{l}\text { Calculated mean } \\
15-120 \mathrm{~min}\end{array}$ \\
\hline \multicolumn{8}{|l|}{ A } \\
\hline$n$ & 5 & 5 & 5 & 4 & 4 & 4 & \\
\hline $\mathrm{PaCO}_{2}$ & $4.1 \pm 0.4^{a}$ & $5.1 \pm 0.4^{e}$ & $5.5 \pm 1^{g}$ & $6.7 \pm 2$ & $6.3 \pm 2$ & $8.1 \pm 2.5$ & 6.3 \\
\hline $\mathrm{PaO}_{2}$ & $48.1 \pm 3.5^{b}$ & $10.9 \pm 5.5^{f}$ & $12.4 \pm 4.1^{h}$ & $11.6 \pm 4.9$ & $9.9 \pm 2.3$ & $8.3 \pm 0.5$ & 10.8 \\
\hline $\mathrm{A}-\mathrm{aDO}_{2}$ & $42.8 \pm 3.7^{c}$ & $79 \pm 5.6$ & $77.2 \pm 3.5$ & $76.8 \pm 3.2$ & $78.8 \pm 1.5$ & $78.5 \pm 2.3$ & 78.1 \\
\hline SBP & $91 \pm 7^{d}$ & $92 \pm 9$ & $98 \pm 7$ & $101 \pm 7$ & $101 \pm 7$ & $93 \pm 5$ & 97 \\
\hline \multicolumn{8}{|c|}{ B } \\
\hline$n$ & 6 & 5 & 2 & 1 & 0 & 0 & \\
\hline $\mathrm{PaCO}_{2}$ & $4.4 \pm 0.7^{a}$ & $7.9 \pm 0.7^{e}$ & $9.2 \pm 0.03^{x}$ & 8.8 & & & 8.3 \\
\hline $\mathrm{PaO}_{2}$ & $50.5 \pm 3.9^{b}$ & $4 \pm 0.4^{f}$ & $4 \pm 0.07^{h}$ & 4.5 & & & 4 \\
\hline $\mathrm{A}-\mathrm{aDO}_{2}$ & $40 \pm 4^{c}$ & $83.2 \pm 1$ & $81.9 \pm 0.04$ & 81.7 & & & 82.7 \\
\hline SBP & $96 \pm 4^{d}$ & $97 \pm 4$ & $99 \pm 4$ & 72 & & & 95 \\
\hline
\end{tabular}

* Values are mean \pm SD. SBP, systolic blood pressure; B/L, before lavage; A/L, after lavage. Group A had lung ventilation + peritoneal ventilation; group B had lung ventilation only. Mortality within $90 \mathrm{~min}=1 / 5$ (group A) and 6/6 (group B); $p=0.006$. Comparing the groups at the same time intervals: ${ }^{a},{ }^{b},{ }^{c},{ }^{d}=\mathrm{NS} ;{ }^{e},{ }^{f},{ }^{g},{ }^{h}=p<0.05$. 


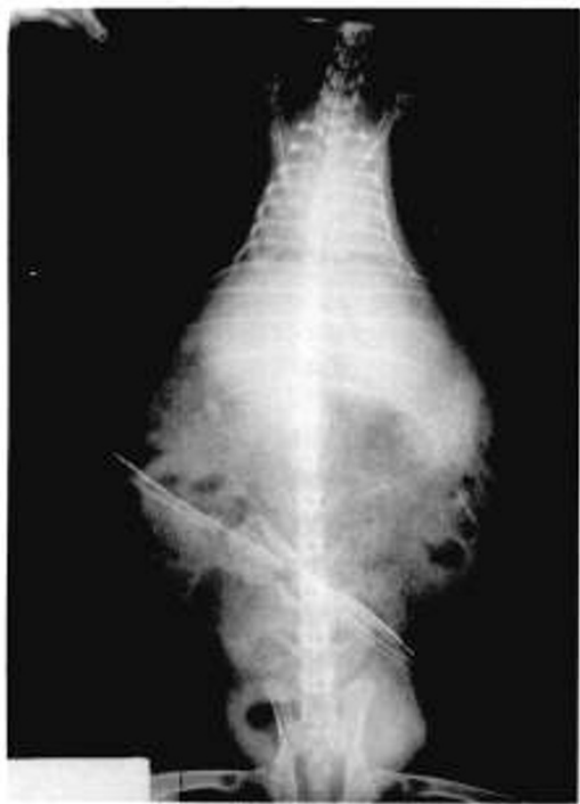

Fig. 1. Chest $x$-ray of a rabbit with severe ARDS caused by saline lung lavage.

present study shows important improvement of $\mathrm{PaO}_{2}$ and $\mathrm{PaCO}_{2}$ values using peritoneal ventilation in rabbits with experimental severe ARDS. The improvement in $\mathrm{PaO}_{2}$ and $\mathrm{PaCO}_{2}$ values was clinically acceptable and statistically significant.

Additional studies are needed, probably in humans with lethal intractable hypoxemia due to severe ARDS, for possible future use of peritoneal ventilation in places where extracorporeal mem- brane oxygenation is not available. Peritoneal ventilation may be considered as an investigational method for extrapulmonary oxygenation in severe intractable hypoxemia caused by ARDS.

\section{REFERENCES}

1. Walker AP, Condon RE 1989 Peritonitis and intraabdominal abscesses. In Schwartz SI, Shires GT. Spencer FC (eds) Principles of Surgery. McGrawHill, New York, pp 1459-1460

2. Bourne G, Smith RG 1927 The value of intravenous and intraperitoneal administration of oxygen. Am J Physiol 82:328-334

3. Cole $F 1951$ Intravenous oxygenation. Anesthesia 12:181-188

4. Singh I, Shah MJ 1940 Intravenous injection of oxygen under normal atmospheric pressure. Lancet 1:922-923

5. Awad JA, Brassard A, Caron MW 1970 Intraperitoneal oxygenation. An experimental study in dogs. Int Surg 53:162-166

6. Awad JA, Brassard A, Caron WM, Cadrin C 1970 Intraperitoneal oxygenation with hydrogen peroxide. Int Surg 54:276-282

7. Klein J, Faithfull NS, Salt PJ, Trouwborst A 1986 Transperitoneal oxygenation with fluorocarbons. Anesth Analg 65:734-738

8. Faithfull NS, Klein J, van der Zee HT, Salt PJ 1984 Whole body oxygenation using intraperitoneal perfusion of fluorocarbons. Br J Anaesth 56:867-872

9. Bilge FB, Bedenbaugh PH, von Recum AF 1989 Peritoneal oxygenation. A feasibility analysis. Biomater Artif Cells Artif Organs 17:413-427

10. Siriwardhana SA, Newfield AM, Lipton JM, Giesecke AH 1990 Oxygen delivery by the peritoneal route. Can J Anaesth 37:S159

11. White GL. Holmes DD 1976 A comparison of ketamine and the combination ketamine-xylazine for effective surgical anesthesia in the rabbit. Lab Anim Sci 26:804-806

12. Sanford TD, Colby ED 1980 Effect of xylazine and ketamine on blood pressure, heart rate and respiratory rate in rabbits. Lab Anim Sci 30:519-523

13. Kuckelt W, Dauberschmidt R, Bender V, Hieronymi U, Mrochen H, Winsel $K$. Meyer M 1981 Experimental investigations in adult respiratory distress syndrome. Repeated pulmonary lavage in Lewe-mini-pigs. Exp Pathol 20:88-104

14. Huber GL, Edmunds LH, Finley TN 1966 Acute effect of saline lung washing on pulmonary mechanics and morphology. Surg Forum 17:113-114

15. Lachmann B, Robertson B, Vogel $\mathrm{J} 1980$ In vivo lung lavage as an experimental model of the respiratory distress syndrome. Acta Anaesthesiol Scand 24:231236

16. West JB 1990 Respiratory Physiology: The Essentials. Williams \& Wilkins, Baltimore 